\title{
PENGARUH KECERDASAN INTELEKTUAL, EMOSIONAL, DAN SPIRITUAL TERHADAP PEMAHAMAN AKUNTANSI (STUDI PADA MAHASISWA FAKULTAS EKONOMI UNIVERSITAS MUHAMMADIYAH MALUKU UTARA)
}

\author{
Muhammad Daud bin Mahmud \\ Program Studi Akuntansi Syariah, IAIN Ternate, Ternate, Maluku Utara, Indonesia \\ daud@iain-ternate.ac.id
}

\begin{abstract}
Abstrak
Penelitian ini bertujuan untuk menguji pengaruh kecerdasan intelektual, emosional, dan spiritual terhadap pemahaman akuntansi mahasiswa baik secara parsial maupun secara simultan. Objek penelitian ini yaitu 58 orang mahasiswa tingkat akhir yang telah menempuh 136 sistem kredit semester (SKS) dan telah lulus mata kuliah wajib pada program studi akuntansi Fakultas Ekonomi Universitas Muhammadiyah Maluku Utara. Penelitian ini menggunakan metode kuantitatif dengan regresi linier berganda sebagai alat analisis. Data yang digunakan terdiri dari data primer dan sekunder. Data primer dalam penelitian ini yaitu hasil tabulasi atas jawaban responden yang diperoleh melalui penyebaran kuesioner, sedangkan data sekunder diperoleh dari nilai mahasiswa di dokumen arsip Program Studi Akuntansi, Fakultas Ekonomi Universitas Muhammadiyah Maluku Utara. Penelitian ini menghasilkan temuan bahwa dari tiga variabel independen yang di uji, variabel kecerdasan intelektual dan kecerdasan spiritual tidak memiliki pengaruh terhadap pemahaman akuntansi (variabel dependen) secara parsial sedangkan variabel kecerdasan emosional berpengaruh terhadap pemahaman akuntansi secara parsial. Sementara ketiga variabel tersebut tidak memiliki pengaruh terhadap variabel dependen secara simultan.
\end{abstract}

Kata kunci: IQ, EQ, SQ, pemahaman akuntansi

\section{THE EFFECTS OF INTELLECTUAL, EMOTIONAL, AND SPIRITUAL INTELLIGENCE IN UNDERSTANDING OF ACCOUNTING (A STUDY ON THE FACULTY OF ECONOMICS'STUDENTS, UNIVERSITAS MUHAMMADIYAH MALUKU UTARA)}

\begin{abstract}
This study aims to examining the effects of intellectual, emotional, and spiritual intelligence on students' understanding of accounting both partially and simultaneously. The objects of this study are 58 final-year students who have taken 136 of academic credits (SKS) and passed the compulsory courses in Accounting Program at the Faculty of Economics, Universitas Muhammadiyah Maluku Utara. This study used quantitative methodology with multiple linear regression as an analysis tool. The data used consists of primary and secondary data. The primary data on this sudy were tabulation results of respondent's answers obtained through questionnaires, while secondary data were obtained from student's scores in the Accounting Program's archives at the Faculty of Economics, Universitas Muhammadiyah Maluku Utara. The results of this study are as follows. The intellectual intelligence and spiritual intelligence do not have any influence in students' understanding of accounting partially while emotional intelligence does. Those three intelligences do not effect the students' understanding of accounting by simultaneously.
\end{abstract}

Keywords: $I Q, E Q, S Q$, understanding of accounting

Article History: Received: 03 Peb 2020 Revised: 26 Mar 2020 Accepted: 08 Apr 2020 


\section{PENDAHULUAN}

Berkembangnya ilmu pengetahuan dan teknologi memiliki dampak yang signifikan terhadap penyelesaian masalah dalam kehidupan manusia. Tidak hanya memberikan dampak positif, perkembangan ilmu pengetahuan dan teknologi juga menyisakan dampak negatif yang menjadi masalah di tengah masyarakat karena belum mampu menumbuhkan moralitas (akhlak) yang mulia (Mulkhan, 1998:29). Diantara akibat negatif itu, ialah kemerosotan moral anak bangsa yang terasa hampir disetiap starata kehidupan termasuk di kalangan mahasiswa (Aziz dan Mangestuti, 2006).

Kemerosotan moral yang terjadi di tengah anak bangsa tak lepas dari tanggung jawab perguruan tinggi. Olehnya itu, perguruan tinggi termasuk di dalamnya penyelenggara program akuntansi saat ini dituntut tidak hanya menghasilkan lulusan yang menguasai kemampuan di bidang akademik tetapi juga mempunyai kemampuan yang bersifat teknis analisis dalam bidang humanistic skill (Yuniani dan Pamudji, 2010). Humanistic skill merupakan salah satu keterampilan yang wajib dimiliki oleh peserta didik karena pada hakikatnya proses pendidikan tidak hanya mentransfer pengetahuan tetapi juga perilaku pada realitas yang sesuai nilai-nilai sosial yang berkembang di tengah masyarakat (Mulawarman, 2006).

Semua ilmu termasuk ilmu akuntansi memang dapat dipelajari dan dipahami hanya dengan menggunakan kecerdasan intelektual saja tetapi untuk mengasah humanistic skill dibutuhkan kecerdasan emosional (Damayanti, 2010), sementara kecerdasan spiritual merupakan landasan yang diperlukan untuk memfungsikan kedua kecerdasan yang disebutkan sebelumnya secara efektif guna mencapai tingkat kecerdasan sempurna atau the ultimate meaning (Nisa, 2009). Ketiga kecerdasan ini dibutuhkan untuk meningkatkan kualitas lulusan perguruan tinggi sekaligus menjadi solusi untuk menghadapi kemerosotan moral anak bangsa yang muncul sebagai akibat negatif dari pesatnya perkembangan ilmu pengetahuan dan teknologi.

Penelitian terkait pemahaman akuntansi yang dipengaruhi oleh kecerdasan mahasiswa telah banyak dilakukan sebelumnya. Penelitian Aziza dan Melandy (2006) menghasilkan temuan bahwa dari lima komponen kecerdasan emosional, hanya pengendalian diri dan empati yang bepengaruh positif terhadap pemahaman akuntansi. Penelitian Tikollah, dkk (2006) menghasilkan temuan bahwa kecerdasan intelektual, kecerdasan emosional, dan kecerdasan spiritual secara simultan berpengaruh terhadap sikap etis mahasiswa akuntansi tetapi secara parsial hanya kecerdasan intelektual yang berpengaruh secara signifikan dan dominan terhadap sikap etis mahasiswa akuntansi. Sedangkan penelitian Damayanti (2010) menghasilkan temuan bahwa pendidikan tinggi akuntansi memiliki pengaruh positif tetapi tidak signifikan terhadap kecerdasan emosional.

Persoalan sosial moral di kalangan mahasiswa umumnya dicirikan dengan sikap arogansi, saling memfitnah sesama teman, rendahnya kepeduliaan sosial, meningkatnya hubungan seks pra-nikah, bahkan merosotnya penghargaan dan rasa hormat terhadap orang tua termasuk dosen. (Aziz dan Mangestuti, 2006). Ciri-ciri kemerosotan moral ini juga yang tampak di kalangan mahasiswa Maluku Utara termasuk mahasiswa program studi akuntansi Universitas Muhammadiyah Maluku Utara. Kemerosotan moral ini tentu menjadi penghambat bagi mahasiswa dalam proses belajarnya sehingga tidak mampu mencapai tujuan pembelajaran secara maksimal dan pada akhirnya moral lulusan pendidikan tinggi yang dipertanyakan. Sejalan dengan persoalan ini, 
dalam bidang akuntansi, Novius dan Arifin (2008) menengaskan bahwa para akuntan profesional cenderung berperilaku tidak bermoral apabila dihadapkan dengan suatu persoalan akuntansi.

Berdasarkan latar belakang dan permasalahan yang diuraikan sebelumnya, maka peneliti merumuskan tujuan penelitian ini yaitu untuk menguji pengaruh kecerdasan intelektual, emosional, dan spiritual terhadap pemahaman mata kuliah akuntansi pada mahasiswa Fakultas Ekonomi Universitas Muhammadiyah Maluku Utara. Hasil penelitian ini diharapkan dapat memberikan kontribusi terhadap pengembangan ilmu pengetahuan melalui konfirmasi atas penelitian yang telah dilakukan sebelumnya untuk kemudian dijadikan pertimbangan dalam penyusunan kurikulum pembelajaran akuntansi di perguruan tinggi khususnya di Universitas Muhammadiyah Maluku Utara.

\section{LANDASAN TEORI}

\section{Kecerdasan Intelektual}

Menurut Zohar dan Marshall (2004), kecerdasan (inteligensi) merupakan kemampuan untuk menyelesaikan masalah dan kemampuan untuk merancang strategi atau sebagai alat yang berguna untuk mencapai tujuan. Inteligensi secara tipikal didefinisikan sebagai kemampuan seseorang untuk beradaptasi dengan lingkungan dan kemampuannya untuk belajar dari pengalaman (Sternberg, 2005). Konsep kecerdasan umumnya mengacu pada kemampuan berpikir dan belajar untuk menggambarkan penerapan keterampilan dan fakta (Clarken, 2009). Kecerdasan umumnya dibagi kedalam tiga bagian yaitu kecerdasan intelektual, kecerdasan emosional, dan kecerdasan spiritual (Zohar dan Marshall 2004). Kecerdasan intelektual adalah kemampuan mental untuk menghadirkan solusi terhadap suatu masalah secara efektif dan efisien (Aziz dan Mangestuti, 2006).

Indikator Pengukuran Kecerdasan Intelektual

Menurut Zohar dan Marshall (2004), kecerdasan intelektual diukur menggunakan skor dari suatu tes kecerdasan intelektual (intelligence quotient atau IQ). Indikator yang dipakai untuk mengukur kecerdasan intelektual terdiri dari tiga domain kognitif yaitu (1) kemampuan spasial, merupakan kemampuan penalaran dan pemahaman terhadap bentuk, (2) kemampuan verbal, merupakan kemampuan penalaran dan pemahaman terhadap bahasa, dan (3) kemampuan numerik, kemampuan penalaran dan pemahaman terhadap angka (Trihandini, 2005, Zohar dan Marshall, 2004). Menurut Sternberg (2005) kecerdasan intelektual dapat diukur dengan kemampuan menganalisis, kemampuan berkreasi, dan kemampuan praktis.

\section{Kecerdasan Emosional}

Emosi merupakan luapan perasaan yang muncul secara tiba-tiba dan surut dalam waktu yang singkat atau reaksi fisiologis dan psikologis seperti kesedihan, kegembiraan, kecintaan, keharuan, atau keberanian yang sifatnya subjektif (KBBI, 2016). Kecerdasan emosional adalah kemampuan mengenali perasaan sendiri, kemampuan membangkitkan perasaan guna mengontrol pikiran, kemampuan memahami makna perasaan, dan kemampuan mengendalikan perasaan secara menyeluruh sehingga dapat membantu perkembangan emosi dan intelektual (Aziza dan Melandy, 2006).

\section{Indikator Pengukuran Kecerdasan Emosional}

Pada dasarnya, kecerdasan emosional dapat diraih dengan cara membaginya ke dalam lima bagian umum dan lima belas subbagian sebagaimana yang dikemukakan oleh Bar-On melalui model of emotional intelligence (Stein dan Book, 2006). Lima bagian umum tersebut yaitu kemampuan intrapersonal, interpersonal, adaptasi, manajemen stres, dan suasana hati secara umum. 


\begin{tabular}{|c|c|}
\hline \multicolumn{2}{|c|}{$\begin{array}{c}\text { Tabel 1. Skala Penilaian Kecerdasan } \\
\text { Emosional }\end{array}$} \\
\hline $\begin{array}{c}\text { Skala } \\
\text { Kecerdasan } \\
\text { Emosional } \\
\end{array}$ & $\begin{array}{c}\text { Kemampuan } \\
\text { kecerdasan emosional } \\
\text { yang dinilai }\end{array}$ \\
\hline \multicolumn{2}{|l|}{ Intrapersonal } \\
\hline $\begin{array}{l}\text { Kesadaran } \\
\text { diri secara } \\
\text { emosional }\end{array}$ & $\begin{array}{l}\text { Kemampuan untuk } \\
\text { menyadari dan } \\
\text { memahami perasaan, } \\
\text { perilaku, dan dampaknya } \\
\text { terhadap orang lain. }\end{array}$ \\
\hline Ketegasan & $\begin{array}{l}\text { Kemampuan untuk } \\
\text { mengekspresikan dan } \\
\text { mempertahankan } \\
\text { kepercayaan, dan } \\
\text { pikiran dengan cara yang } \\
\text { konstruktif. }\end{array}$ \\
\hline Independen & $\begin{array}{l}\text { Kemampuan untuk } \\
\text { mandiri dan bebas dari } \\
\text { ketergantungan } \\
\text { emosional pada orang } \\
\text { lain. }\end{array}$ \\
\hline Harga diri & $\begin{array}{l}\text { Kemampuan untuk } \\
\text { menghormati dan } \\
\text { menerima kekuatan dan } \\
\text { lemahan diri. }\end{array}$ \\
\hline $\begin{array}{l}\text { Aktualisasi } \\
\text { diri }\end{array}$ & $\begin{array}{l}\text { Kemampuan untuk } \\
\text { menetapkan tujuan } \\
\text { pribadi dan menyadari } \\
\text { potensi diri. }\end{array}$ \\
\hline \multicolumn{2}{|l|}{ Interpersonal } \\
\hline Empati & $\begin{array}{l}\text { Kemampuan untuk } \\
\text { melihat dunia dari sudut } \\
\text { pandang orang lain. }\end{array}$ \\
\hline $\begin{array}{l}\text { Tanggung } \\
\text { jawab sosial }\end{array}$ & $\begin{array}{l}\text { Kemampuan untuk } \\
\text { menjadi kooperatif dan } \\
\text { berkontribusi dalam } \\
\text { kelompok sosial. }\end{array}$ \\
\hline \multicolumn{2}{|c|}{ Kemampuan beradaptasi } \\
\hline $\begin{array}{l}\text { Penyelesaian } \\
\text { masalah }\end{array}$ & $\begin{array}{l}\text { Kemampuan untuk } \\
\text { memecahkan masalah } \\
\text { yang bersifat pribadi dan } \\
\text { interpersonal. }\end{array}$ \\
\hline $\begin{array}{l}\text { Pengujian } \\
\text { realitas }\end{array}$ & $\begin{array}{l}\text { Kemampuan } \\
\text { melihat segala sesuatu } \\
\text { secara realistis bukan } \\
\text { seperti yang diinginkan. }\end{array}$ \\
\hline
\end{tabular}

\begin{tabular}{|c|l|}
\hline Fleksibel & $\begin{array}{l}\text { Kemampuan untuk } \\
\text { beradaptasi dan } \\
\text { menyesuaikan } \\
\text { pemikiran, perilaku, } \\
\text { dan perasaan dengan } \\
\text { informasi baru. }\end{array}$ \\
\hline Manajemen stres \\
\hline Toleransi \\
stres & $\begin{array}{l}\text { Kemampuan untuk } \\
\text { menahan kejadian } \\
\text { buruk secara efektif } \\
\text { dan mengatasinya } \\
\text { secara konstruktif. }\end{array}$ \\
\hline Kontrol & $\begin{array}{l}\text { Kemampuan untuk } \\
\text { menolak atau } \\
\text { menunda dorongan } \\
\text { hati atau godaan untuk } \\
\text { bertindak. }\end{array}$ \\
\hline Suasana hati secara umum \\
\hline Kebahagiaan & $\begin{array}{l}\text { Kemampuan untuk } \\
\text { merasa puas dengan } \\
\text { diri sendiri, orang } \\
\text { lain, dan kehidupan } \\
\text { secara umum. }\end{array}$ \\
\hline Optimisme & $\begin{array}{l}\text { Kemampuan untuk } \\
\text { menjadi positif dan } \\
\text { melihat sisi } \\
\text { kehidupan yang lebih } \\
\text { cerah. }\end{array}$ \\
\hline Sumber: Stein and \\
Beok (2006)
\end{tabular}

Sumber: Stein and Book (2006)

\section{Kecerdasan Spiritual}

Kecerdasan spiritual adalah kecerdasan jiwa yang memungkinkan manusia untuk mengintegrasikan banyak fragmen kehidupan, aktivitas, dan keberadaannya (Zohar and Marshall 2004). Kecerdasan spiritual juga didefinisikan sebagai kemampuan untuk menerapkan dan mewujudkan sumber daya dan kualitas spiritual untuk meningkatkan fungsi dan kesejahteraan (Arman 2007).

Menurut (Howard et al. 2009) kecerdasan spiritual adalah kemampuan untuk membangun sebuah makna secara intuitif dengan melihat keterkaitan antara pengalaman hidup dan kondisi batin dari jiwa seseorang. 


\section{Indikator Pengukuran Kecerdasan Spiritual}

Menurut Emmons (2000), terdapat lima kemampuan inti yang dapat digunakan untuk mendefinisikan kecerdasan spiritual, yaitu (a) kapasitas transendensi, (b) kemampuan untuk memasuki kondisi kesadaran spiritual yang tinggi, (c) kemampuan untuk menginvestasikan aktivitas keseharian, peristiwa, dan hubungan dengan rasa sakral, (d) kemampuan memanfaatkan sumber daya spiritual untuk menyelesaikan masalah dalam kehidupan, (e) kapasitas untuk berperilaku atau berbudi luhur (untuk menunjukkan permintaan maaf, mengucapkan terima kasih, menjadi rendah hati, dan menunjukkan kasih sayang).

Menurut Zohar dan Marshall (2004), terdapat dua belas kriteria untuk seseorang dapat dikatakan berada pada kondisi kecerdasan spiritual yang tinggi, yaitu:

a. Kesadaran diri. Kesadaran akan tujuan hidup;

b. Spontanitas, bersifat responsif terhadap kehidupan dan semua yang ada di dalamnya;

c. Memiliki visi dan nilai hidup. Bertindak sesuai prinsip dan keyakinan yang mendalam, dan menjalani kehidupan sesuai dengan prinsip dan keyakinan tersebut;

d. Holisme. Kemampuan untuk melihat pola, hubungan, koneksi yang lebih besar. Rasa memiliki yang kuat;

e. Kasih sayang. Kualitas perasaan dan empati yang mendalam;

f. Menghargai perbedaan. Menghargai orang lain dan kondisi dimana perbedaan bukanlah hal yang familiar bagi mereka;

g. Independensi. Dapat mempertahankan apa yang diyakini; h. Kecenderungan untuk bertanya persoalan yang fundamental;

i. Kemampuan untuk membingkai ulang. Mundur dari masalah atau situasi dan mencari gambaran yang lebih besar;

j. Pemanfaatan kesulitan secara positif. Kemampuan untuk belajar dari kesalahan, untuk melihat masalah sebagai peluang;

k. Kerendahan hati. Dasar kritik diri dan penilaian kritis; dan

1. Perasaan terpanggil untuk bekerja. Terpanggil untuk melayani sesuatu yang lebih besar dari diri sendiri. Berterimakasih kepada mereka yang telah membantu dan berkeinginan untuk memberikan sesuatu kembali. Dasar untuk pemimpin yang melayani.

\section{Pemahaman Akuntansi}

Secara etimologi paham adalah mengerti betul tentang suatu hal (KBBI, 2016). Orang yang memiliki pemahaman akuntansi adalah orang yang pandai dan mengerti betul tentang akuntansi baik secara teori maupun praktiknya (Aziza dan Melandy, 2006). Menurut Suwardjono (2005), pengetahuan akuntansi dapat dilihat dari dua aspek yaitu disiplin ilmu dan profesi. Pengetahuan akuntansi yang diajarkan di perguruan tinggi merupakan bagian dari pengembangan disiplin ilmu pengetahuan, sedangkan pengetahuan profesi (keahlian) merupakan ilmu akuntansi yang diaplikasikan secara langsung dalam praktik profesi akuntansi.

\section{Indikator Pengukuran Pemahaman Akuntansi}

Indikator yang digunakan untuk mengukur tingkat pemahaman akuntansi yaitu nilai mahasiswa dalam laporan hasil studi untuk mata kuliah pengantar akuntansi 1, pengantar akuntansi 2, akuntansi keuangan menengah 1, akuntansi keuangan menengah 2, akuntansi keuangan lanjutan 1, 
akuntansi keuangan lanjutan 2, pengauditan 1, dan pengauditan 2. Semua mata kuliah ini merupakan mata kuliah wajib bagi mahasiswa yang mengambil jurusan akuntansi.

\section{Kerangka Analisis}

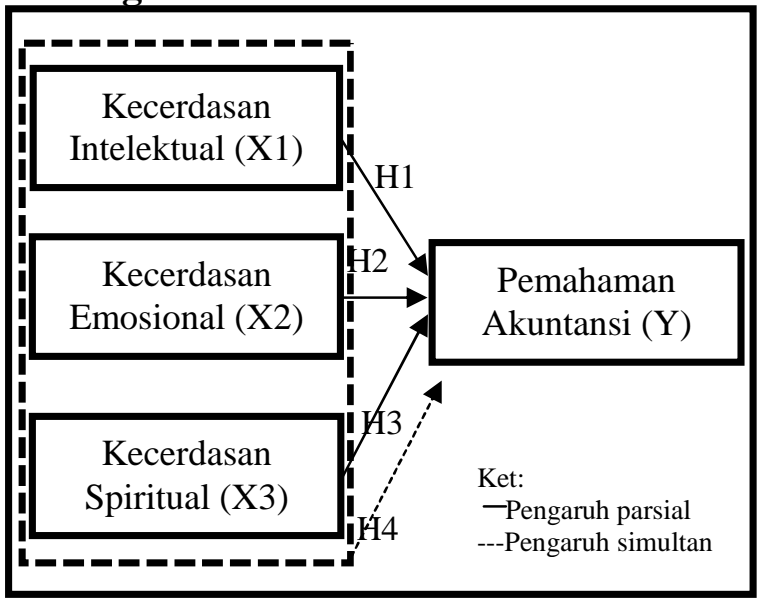

Gambar 1. Kerangka Dasar Penelitian

\section{Pengembangan Hipotesis}

Kecerdasan manusia secara umum terbagi menjadi tiga bagian yaitu kecerdasan intelektual, kecerdasan emosional, dan kecerdasan spiritual (Zohar and Marshall 2004). Kecerdasan intelektual adalah kemampuan menghadirkan solusi terhadap suatu masalah secara efektif dan efisien (Aziz dan Mangestuti, 2006). Kemampuan menghadirkan solusi dalam pemecahan masalah ketika mempelajari ilmu akuntansi merupakan faktor penentu keberhasilan belajar. Penelitian Aziz dan Mangestuti (2006) menghasilkan temuan bahwa kecerdasan intelektual berpengaruh terhadap agresivitas mahasiswa. Hasil penelitian yang sama juga ditemukan oleh penelitian Tikollah, dkk (2006) bahwa kecerdasan intelektual berpengaruh terhadap sikap etis mahasiswa. Dengan demikian, hipotesis satu penelitian ini dirumuskan sebagai berikut:

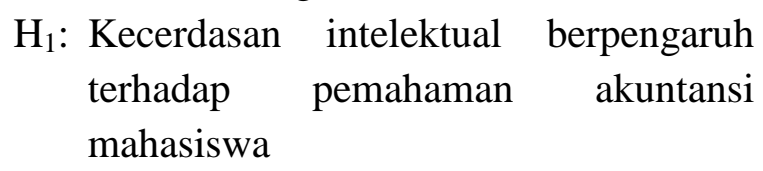

Selain kecerdasan intelektual, ada kecerdasan emosional, yang diklaim oleh Goleman (2003) sebagai kemampuan terbesar yang mempengaruhi kesuksesan seseorang dalam bekerja. Tugas utama mahasiswa adalah belajar sehingga belajar bagi mahasiswa dianalogikan bekerja bagi pekerja. Olehnya itu, kecerdasan emosional sangat dibutuhkan oleh mahasiswa untuk kesuksesan belajar. Penelitian Trisnawati dan Suryaningrum (2003) menghasilkan temuan bahwa kecerdasan emosional tidak berpengaruh terhadap tingkat pemahaman akuntansi. Hasil penelitian yang sama juga ditemukan oleh penelitian yang dilakukan oleh Aziza dan Melandy (2006), dari lima kriteria kecerdasan emosional, tiganya tidak berpengaruh terhadap tingkat pemahaman akuntansi. Penelitian yang dilakukan Tikollah, dkk (2006) menghasilkan temuan bahwa kecerdasan emosional tidak berpengaruh terhadap sikap etis mahasiswa. Dengan demikian, hipotesis dua penelitian ini dirumuskan sebagai berikut:
$\mathrm{H}_{2}$ : Kecerdasan emosional tidak berpengaruh terhadap pemahaman akuntansi mahasiswa

Kecerdasan ketiga yang ada pada manusia yaitu kecerdasan spiritual. Kebagahagiaan yang diperoleh seseorang melalui kecerdasan spiritual menjadikannya dapat bekerja dan berkarya lebih maksimal (Zohar and Marshall 2004). Jika teori ini dilekatkan pada mahasiswa maka kebahagiaan mahasiswa menjadi faktor penting dalam menghasilkan suatu karya. Penelitian Tikollah, dkk (2006) menghasilkan temuan bahwa kecerdasan spiritual secara parsial tidak berpengaruh terhadap sikap etis mahasiswa. Meskipun demikian kecerdasan spiritual merupakan bagian sentral dari ketiga kecerdasan yang tidak dapat dipisahkan dalam kehidupan 
seseorang sehingga pengembangannya harus dilakukan secara proporsional dan komprehensif. Penelitian yang dilakukan oleh Aziz dan Mangestuti (2006) menghasilkan temuan bahwa kecerdasan spiritual memiliki pengaruh sangat signifikan terhadap agresivitas mahasiswa. Dengan demikian, hipotesis tiga penelitian ini dirumuskan sebagai berikut:
$\mathrm{H}_{3}$ : Kecerdasan spiritual berpengaruh terhadap pemahaman akuntansi mahasiswa

\section{Penelitian Trihandini (2005)} menghasilkan temuan bahwa kecerdasan intelektual, emosional, dan spiritual secara bersama-sama mempengaruhi kinerja karyawan. Hasil penelitian yang sama juga ditemukan oleh Tikollah, dkk (2006) bahwa ketiga kecerdasan tersebut secara bersamasama berpengaruh terhadap sikap etis mahasiswa. Hasil penelitian Aziz dan Mangestuti (2006) juga menemukan hal yang sama dimana ketiga kecerdasan tersebut secara bersama-sama mempengaruhi agresivitas mahasiswa. Dari temuan penelitian sebelumnya, hipotesis empat penelitian ini dirumuskan sebagai berikut:

$\mathrm{H}_{4}$ : Kecerdasan intelektual, emosional, dan spiritual secara simultan berpengaruh terhadap pemahaman akuntansi mahasiswa

\section{METODE PENELITIAN}

Penelitian ini menggunakan metode kuantitatif dengan alat analisis regresi linier berganda yang didasarkan pada data primer dan sekunder. Data primer dalam penelitian ini yaitu hasil tabulasi atas jawaban responden yang diperoleh melalui penyebaran kuesioner, sementara data sekunder diperoleh dari nilai mahasiswa di dokumen arsip program studi akuntansi Universitas Muhammadiyah Maluku Utara.

Ukuran sampel ditentukan menggunakan formula $\mathrm{n}=\mathrm{N} /\left[1+\mathrm{N}(\mathrm{e})^{2}\right]$ dimana " $n$ " adalah ukuran sampel, "N" adalah ukuran populasi, dan "e" adalah presisi. Formula ini digunakan untuk mengkalkulasi ukuran sampel dengan derajat kepercayaan $95 \%$ dan tingkat presisi diasumsikan 5\% (Singh dan Masuku, 2014). Populasi dalam penelitian ini terdiri dari 138 orang mahasiswa tingkat akhir di Program Studi Akuntansi yang telah menyelesaikan 136 Sistem Kredit Semester (SKS) dan telah lulus mata kuliah wajib. Dari jumlah populasi yang ada, sampel yang diperoleh dalam penelitian ini yaitu 58 orang mahasiswa.

\section{HASIL DAN PEMBAHASAN}

Data dalam penelitian ini diperoleh dari penyebaran kuesioner kepada mahasiswa program studi akuntansi Universitas Muhammadiyah Maluku Utara yang telah menempuh 136 SKS. Kuesioner disebarkan sebanyak 65 eksemplar. Sebelum kuesioner dibagikan kepada responden, terlebih dahulu dilakukan pretest terhadap 30 orang mahasiswa program studi akuntansi semester lima. Berikut adalah hasil uji validitas dan reliabilitas kuesioner.

\section{Hasil Uji Validitas}

Pengujian validitas dalam penelitian ini menggunakan pengujian statistik Product Moment Pearson dengan taraf signifikansi $5 \%$. Ketentuannya adalah apabila $r_{\text {hitung }}$ lebih besar dari $r_{\text {tabel }}$ maka item pertanyaan yang ada pada kuesioner dinyatakan valid. Dengan alpha 0.05 dan degree of fredom $(\mathrm{df})=56$ yang diperoleh dari (58-2), maka $r_{\text {tabel }}$ yang digunakan sebagai pembanding $r_{\text {hitung }}$ dalam penelitian ini adalah 0.218 . 
Tabel 1.

Hasil Uji Validitas

\begin{tabular}{|c|c|c|c|c|c|}
\hline \multicolumn{6}{|c|}{ Variabel Kecerdasan Intelektual } \\
\hline \multirow{2}{*}{$\begin{array}{c}\text { Item } \\
\text { Pert } \\
\text { anya } \\
\text { an }\end{array}$} & \multicolumn{2}{|c|}{ pre-test } & \multicolumn{2}{|c|}{$\begin{array}{c}\text { pasca } \\
\text { penelitian }\end{array}$} & \multirow[b]{2}{*}{ Ket } \\
\hline & $\begin{array}{c}\mathbf{r} \\
\text { hitung }\end{array}$ & $\begin{array}{c}r \\
\text { tabel }\end{array}$ & $\begin{array}{c}\mathbf{r} \\
\text { hitun } \\
\mathbf{g}\end{array}$ & $\begin{array}{c}r \\
\text { tabel }\end{array}$ & \\
\hline 1 & 0.800 & & 0.680 & & Valid \\
\hline 2 & 0.753 & & 0.734 & & Valid \\
\hline 3 & 0.786 & & 0.723 & & Valid \\
\hline 4 & 0.760 & & 0.709 & & Valid \\
\hline 5 & 0.348 & 0361 & 0.548 & ( 218 & Valid \\
\hline 6 & 0.833 & 0.301 & 0.738 & 0.218 & Valid \\
\hline 7 & 0.723 & & 0.714 & & Valid \\
\hline 8 & 0.525 & & 0.582 & & Valid \\
\hline 9 & 0.724 & & 0.757 & & Valid \\
\hline 10 & 0.670 & & 0.564 & & Valid \\
\hline
\end{tabular}

Sumber: Data primer diolah (2018)

Tabel 2.

Hasil Uji Validitas Variabel Kecerdasan Emosional

\begin{tabular}{|c|c|c|c|c|c|}
\hline \multirow{2}{*}{$\begin{array}{c}\text { Item } \\
\text { Perta } \\
\text { nyaa } \\
\text { n }\end{array}$} & \multicolumn{2}{|c|}{ pre-test } & \multicolumn{2}{|c|}{$\begin{array}{c}\text { pasca } \\
\text { penelitian }\end{array}$} & \multirow[b]{2}{*}{ Ket } \\
\hline & $\begin{array}{c}\mathbf{r} \\
\text { hitung }\end{array}$ & $\begin{array}{c}\mathbf{r} \\
\text { tabel }\end{array}$ & $\begin{array}{c}\mathbf{r} \\
\text { hitun } \\
\mathbf{g}\end{array}$ & $\begin{array}{c}r \\
\text { tabel }\end{array}$ & \\
\hline 1 & 0.726 & & 0.711 & & Valid \\
\hline 2 & 0.579 & & 0.577 & & Valid \\
\hline 3 & 0.509 & & 0.514 & & Valid \\
\hline 4 & 0.697 & & 0.695 & & Valid \\
\hline 5 & 0.451 & & 0.497 & & Valid \\
\hline 6 & 0.497 & & 0.441 & & Valid \\
\hline 7 & 0.513 & & 0.635 & & Valid \\
\hline 8 & 0.419 & & 0.510 & & Valid \\
\hline 9 & 0.558 & & 0.586 & & Valid \\
\hline 10 & 0.855 & 0361 & 0.804 & 0218 & Valid \\
\hline 11 & 0.497 & 0.361 & 0.622 & 0.218 & Valid \\
\hline 12 & 0.461 & & 0.570 & & Valid \\
\hline 13 & 0.483 & & 0.582 & & Valid \\
\hline 14 & 0.704 & & 0.676 & & Valid \\
\hline 15 & 0.768 & & 0.730 & & Valid \\
\hline 16 & 0.777 & & 0.736 & & Valid \\
\hline 17 & 0.550 & & 0.628 & & Valid \\
\hline 18 & 0.500 & & 0.601 & & Valid \\
\hline 19 & 0.405 & & 0.600 & & Valid \\
\hline 20 & 0.554 & & 0.670 & & Valid \\
\hline
\end{tabular}

Sumber: Data primer diolah (2018)

Tabel 3.

Hasil Uji Validitas Variabel Kecerdasan Spiritual

\begin{tabular}{cccccc}
\hline $\begin{array}{c}\text { Item } \\
\text { Perta }\end{array}$ & \multicolumn{2}{c}{ pre-test } & \multicolumn{2}{c}{$\begin{array}{c}\text { pasca } \\
\text { penelitian }\end{array}$} & \multirow{2}{*}{ Ket } \\
\cline { 2 - 5 } $\begin{array}{c}\text { nyaa } \\
\text { n }\end{array}$ & $\begin{array}{c}\mathbf{r} \\
\text { hitung }\end{array}$ & $\begin{array}{c}\mathbf{r} \\
\text { tabel }\end{array}$ & $\begin{array}{c}\mathbf{r} \\
\text { hitung }\end{array}$ & $\begin{array}{c}\mathbf{r} \\
\text { tabel }\end{array}$ & \\
\hline 1 & 0.626 & 0.361 & 0.589 & 0.218 & Valid
\end{tabular}

\begin{tabular}{cccc}
2 & 0.636 & 0.583 & Valid \\
3 & 0.515 & 0.495 & Valid \\
4 & 0.644 & 0.527 & Valid \\
5 & 0.734 & 0.827 & Valid \\
6 & 0.541 & 0.568 & Valid \\
7 & 0.646 & 0.482 & Valid \\
8 & 0.498 & 0.584 & Valid \\
9 & 0.608 & 0.652 & Valid \\
10 & 0.633 & 0.295 & Valid \\
11 & 0.695 & 0.757 & Valid \\
12 & 0.770 & 0.787 & Valid \\
13 & 0.547 & 0.699 & Valid \\
14 & 0.568 & 0.666 & Valid \\
15 & 0.644 & 0.723 & Valid \\
\hline
\end{tabular}

Sumber: Data primer diolah (2018)

Tabel 4.

Hasil Uji Validitas

Variabel Pemahaman Akuntansi

\begin{tabular}{|c|c|c|c|c|c|}
\hline \multirow{2}{*}{$\begin{array}{c}\text { Item } \\
\text { Perta } \\
\text { nyaa } \\
\text { n }\end{array}$} & \multicolumn{2}{|c|}{ pre-test } & \multicolumn{2}{|c|}{$\begin{array}{c}\text { pasca } \\
\text { penelitian }\end{array}$} & \multirow[b]{2}{*}{ Ket } \\
\hline & $\begin{array}{c}\mathbf{r} \\
\text { hitung }\end{array}$ & $\begin{array}{c}r \\
\text { tabel }\end{array}$ & $\begin{array}{c}\mathbf{r} \\
\text { hitun } \\
\mathbf{g}\end{array}$ & $\begin{array}{c}\mathbf{r} \\
\text { tabel }\end{array}$ & \\
\hline 1 & 0.591 & \multirow{8}{*}{0.361} & 0.578 & \multirow{8}{*}{0.218} & Valid \\
\hline 2 & 0.847 & & 0.778 & & Valid \\
\hline 3 & 0.598 & & 0.712 & & Valid \\
\hline 4 & 0.837 & & 0.777 & & Valid \\
\hline 5 & 0.715 & & 0.831 & & Valid \\
\hline 6 & 0.621 & & 0.378 & & Valid \\
\hline 7 & 0,613 & & 0.578 & & Valid \\
\hline 8 & 0.591 & & 0.778 & & Valid \\
\hline
\end{tabular}

Sumber: Data primer diolah (2018)

\section{Hasil Uji Reliabilitas}

Pengukuran reliabilitas dilakukan dengan uji statistik Cronbach Alpha (á). Suatu variabel dikatakan reliabel jika nilai Cronbach Alphanya lebih besar dari angka 0.60 (Nunally, 1960 dalam Ghozali, 2006).

Tabel 5.

Hasil Uji Reliabilitas

\begin{tabular}{lccccc}
\hline \multicolumn{1}{c}{ Variabel } & $\begin{array}{c}\text { Nilai } \\
\text { Cronbach }\end{array}$ & $\begin{array}{c}\text { N. } \\
\text { Of }\end{array}$ & $\begin{array}{c}\text { Batas } \\
\text { Reliab }\end{array}$ & Ket \\
& Alpha & Item & el & \\
\hline Kecerdasan Intelektual & 0.866 & 10 & & Reliabel \\
Kecerdasan Emosional & 0.916 & 20 & 0.6 & Reliabel \\
Kecerdasan Spiritual & 0.883 & 15 & & Reliabel \\
Pemahaman Akuntansi & 0.821 & 8 & & Reliabel \\
\hline
\end{tabular}

Sumber: Data primer diolah (2018)

\section{Hasil Analisis Deskriptif}

Tabel 6.

Deskripsi Variabel Kecerdasan Intelektual 


\begin{tabular}{|c|c|c|c|c|c|c|}
\hline $\begin{array}{c}\text { Item } \\
\text { Pertanyaan }\end{array}$ & $\begin{array}{l}\text { ST } \\
\text { S }\end{array}$ & $\begin{array}{l}\mathbf{T} \\
\mathbf{S}\end{array}$ & $\begin{array}{l}\mathbf{R} \\
\mathbf{R}\end{array}$ & $\mathbf{S}$ & $\begin{array}{l}\mathbf{S} \\
\mathbf{S}\end{array}$ & Mean \\
\hline Pertanyaan 1 & 2 & 1 & 4 & 35 & 16 & 4.07 \\
\hline Pertanyaan 2 & 2 & 1 & 12 & 27 & 16 & 3.93 \\
\hline Pertanyaan 3 & 0 & 1 & 10 & 35 & 12 & 4.00 \\
\hline Pertanyaan 4 & 2 & 0 & 6 & 38 & 12 & 4.00 \\
\hline Pertanyaan 5 & 1 & 2 & 13 & 30 & 12 & 3.86 \\
\hline Pertanyaan 6 & 2 & 0 & 17 & 29 & 10 & 3.78 \\
\hline Pertanyaan 7 & 2 & 2 & 9 & 30 & 15 & 3.93 \\
\hline Pertanyaan 8 & 0 & 4 & 9 & 35 & 10 & 3.88 \\
\hline Pertanyaan 9 & 0 & 3 & 14 & 28 & 13 & 3.88 \\
\hline Pertanyaan 10 & 1 & 2 & 8 & 35 & 12 & 3.95 \\
\hline
\end{tabular}

Sumber: Data primer diolah (2018)

Dari sepuluh pertanyaan yang
diajukan untuk menilai pengaruh kecerdasan intelektual terhadap pemahaman akuntansi, rata-rata responden menjawab ragu-ragu atau setuju. Artinya rata-rata responden masih ragu dengan kemampuan intelektual mereka baik kemampuan spasial, kemampuan, verbal, maupun kemampuan numerik.

\section{Tabel 7.}

Deskripsi Variabel Kecerdasan Emosional

\begin{tabular}{lcccccc}
\hline Item & ST & T & R & S & S & Mean \\
Pertanyaan & S & S & R & & S & \\
\hline Pertanyaan 1 & 1 & 1 & 6 & 29 & 21 & 4.17 \\
Pertanyaan 2 & 0 & 2 & 2 & 37 & 17 & 4.19 \\
Pertanyaan 3 & 1 & 0 & 1 & 31 & 25 & 4.36 \\
Pertanyaan 4 & 1 & 2 & 21 & 25 & 9 & 3.67 \\
Pertanyaan 5 & 0 & 1 & 6 & 26 & 25 & 4.29 \\
Pertanyaan 6 & 0 & 3 & 5 & 29 & 21 & 4.17 \\
Pertanyaan 7 & 0 & 2 & 14 & 31 & 11 & 3.88 \\
Pertanyaan 8 & 0 & 0 & 11 & 35 & 12 & 4.02 \\
Pertanyaan 9 & 0 & 0 & 5 & 31 & 22 & 4.29 \\
Pertanyaan 10 & 0 & 4 & 11 & 31 & 12 & 3.88 \\
Pertanyaan 11 & 1 & 5 & 7 & 31 & 14 & 3.90 \\
Pertanyaan 12 & 1 & 2 & 10 & 32 & 13 & 3.93 \\
Pertanyaan 13 & 0 & 2 & 10 & 30 & 16 & 4.03 \\
Pertanyaan 14 & 1 & 3 & 14 & 30 & 10 & 3.78 \\
Pertanyaan 15 & 3 & 1 & 13 & 27 & 14 & 3.83 \\
Pertanyaan 16 & 1 & 4 & 9 & 34 & 10 & 3.83 \\
Pertanyaan 17 & 0 & 5 & 13 & 30 & 10 & 3.78 \\
Pertanyaan 18 & 1 & 0 & 3 & 33 & 21 & 4.26 \\
Pertanyaan 19 & 0 & 1 & 3 & 35 & 19 & 4.24 \\
Pertanyaan 20 & 0 & 2 & 7 & 32 & 17 & 4.10 \\
\hline Sumber: Data
\end{tabular}

Sumber: Data primer diolah (2018)

Dari dua puluh pertanyaan yang diajukan untuk menilai pengaruh kecerdasan emosional terhadap pemahaman akuntansi, rata-rata responden menjawab setuju dan sangat setuju. Artinya rata-rata responden yakin akan kemampuan dalam mengendalikan emosi mereka, baik kemampuan mengenali diri, mengendalikan diri, memotivasi, berempati, maupun bersosialiasi.

Tabel 8.

Deskripsi Variabel Kecerdasan Emosional

\begin{tabular}{lcccccc}
\hline $\begin{array}{c}\text { Item } \\
\text { Pertanyaan }\end{array}$ & STS & $\mathbf{T}$ & $\mathbf{R}$ & $\mathbf{S}$ & $\mathbf{S}$ & Mean \\
\hline Pertanyaan 1 & 1 & 0 & 6 & 36 & 15 & 4.10 \\
Pertanyaan 2 & 1 & 2 & 5 & 33 & 17 & 4.07 \\
Pertanyaan 3 & 0 & 2 & 13 & 33 & 10 & 3.88 \\
Pertanyaan 4 & 0 & 1 & 2 & 34 & 21 & 4.29 \\
Pertanyaan 5 & 4 & 4 & 11 & 27 & 12 & 3.67 \\
Pertanyaan 6 & 1 & 1 & 14 & 30 & 12 & 3.88 \\
Pertanyaan 7 & 0 & 0 & 7 & 30 & 21 & 4.24 \\
Pertanyaan 8 & 4 & 2 & 10 & 31 & 11 & 3.73 \\
Pertanyaan 9 & 0 & 2 & 7 & 30 & 19 & 4.14 \\
Pertanyaan 10 & 0 & 1 & 8 & 36 & 13 & 4.05 \\
Pertanyaan 11 & 0 & 1 & 6 & 30 & 21 & 4.22 \\
Pertanyaan 12 & 0 & 3 & 12 & 35 & 8 & 3.88 \\
Pertanyaan 13 & 1 & 0 & 10 & 42 & 5 & 3.86 \\
Pertanyaan 14 & 1 & 1 & 8 & 37 & 11 & 3.97 \\
Pertanyaan 15 & 3 & 2 & 10 & 29 & 14 & 3.84 \\
\hline Sumber: Data & rim
\end{tabular}

Sumber: Data primer diolah (2018)

Dari lima belas pertanyaan yang diajukan untuk menilai pengaruh kecerdasan spiritual terhadap pemahaman akuntansi, rata-rata responden menjawab ragu-ragu atau setuju. Artinya rata-rata responden masih ragu dengan kemampuan spiritual mereka baik kemampuan yang sifatnya sadar diri, pemaaf, objektif, holistik, dan mandiri.

Tabel 9.

Deskripsi Variabel Pemahaman Akuntansi

\begin{tabular}{lcccccc}
$\begin{array}{c}\text { Mata } \\
\text { Kuliah }\end{array}$ & $\begin{array}{c}\text { Nil } \\
\text { ai A }\end{array}$ & $\begin{array}{c}\text { Nil } \\
\text { ai B }\end{array}$ & $\begin{array}{c}\text { Nil } \\
\text { ai C }\end{array}$ & $\begin{array}{c}\text { Nil } \\
\text { ai D }\end{array}$ & $\begin{array}{c}\text { Nil } \\
\text { ai E }\end{array}$ & Mean \\
\hline PA 1 & 23 & 35 & 0 & 0 & 0 & 4.40 \\
PA 2 & 30 & 27 & 1 & 0 & 0 & 4.50 \\
AKM 1 & 28 & 23 & 5 & 1 & 1 & 4.31 \\
AKM 2 & 22 & 28 & 6 & 1 & 1 & 4.19 \\
AKL 1 & 30 & 21 & 6 & 1 & 0 & 4.38 \\
AKL 2 & 27 & 25 & 3 & 2 & 1 & 4.29 \\
Audit 1 & 21 & 28 & 8 & 1 & 0 & 4.19 \\
Audit 2 & 16 & 26 & 9 & 7 & 0 & 3.76 \\
\hline
\end{tabular}

Sumber: Data primer diolah (2018)

Dari delapan mata kuliah wajib akuntansi yang dijadikan patokan untuk menilai kemampuan pemahaman akunatnsi, rata-rata nilai responden di kartu hasil studi (KHS) adalah " $A$ " dan "B" (80-100). 
Artinya hampir keseluruhan responden memiliki pemahaman tentang ilmu akuntansi yang memadai.

\section{Hasil Uji Hipotesis \\ Hasil Uji Individual}

Pengujian pengaruh kecerdasan intelektual, emosional, dan spiritual terhadap pemahaman akuntansi secara parsial dilakukan menggunakan uji-t. Pengujian dilakukan dengan tingkat signifikansi 0,05 . Hasil pengujiannya dapat dilihat pada tabel di bawah.

Tabel 10.

\begin{tabular}{llccc}
\multicolumn{4}{c}{$\begin{array}{c}\text { Hasil Uji Individual (Uji-t) } \\
\text { Coefficients }^{\mathbf{a}}\end{array}$} \\
\multicolumn{1}{c}{ Model } & B & t & Sig. \\
\hline $1 \quad$ (Constant) & 4.380 & 6.631 & .000 \\
& Intelektual & -.096 & -.580 & .564 \\
& Q & & & \\
Emosional & .370 & 1.775 & .042 \\
Q & & & \\
& Spiritual Q & -.309 & -1.411 & .164 \\
\hline
\end{tabular}

a. Dependent Variable: Pemahaman Ak.

Sumber: Data primer diolah (2018)

Nilai probabilitas signifikan pada hasil uji parameter individual (uji-t) untuk varibel kecerdasan intelektual dan kecerdasan spiritual lebih besar dari nilai presisi yang ditolerir sehingga variabel kecerdasan intelektual dan spiritual dapat disimpulkan tidak memiliki pengaruh terhadap pemahaman akuntansi mahasiswa. Variabel kecerdasan emosional disimpulkan berpengaruh terhadap pemahaman akuntansi mahasiswa karena nilai probabilitas signifikan pada hasil uji-t lebih besar dari nilai presisi yang ditolelir. Dengan demikian, keempat hipotesis yang diajukan dalam penelitian ini semunya tertolak.

Hasil penelitian ini berbeda dengan hasil penelitian Aziz dan Mangestuti (2006), Tikollah, dkk (2006), dan Trihandini (2005) dimana kecerdasan intelektual memiliki pengaruh terhadap kinerja, agresivitas, maupun sikap etis seseorang. Hasil penelitian ini tidak mendukung hasil penelitian Aziza dan Melandy (2006), Tikollah, dkk (2006), dan Trisnawati dan
Suryaningrum (2003) dimana kecerdasan emosional tidak memiliki pengaruh terhadap tingkat pemahaman dan sikap etis seseorang. Hasil penelitian ini juga berbeda dengan hasil penelitian Aziz dan Mangestuti (2006) dimana kecerdasan spiritual memiliki pengaruh sangat signifikan terhadap agresivitas mahasiswa.

\section{Hasil Uji Simultan}

Pengujian pengaruh kecerdasan intelektual, emosional, dan spiritual terhadap pemahaman akuntansi secara simultan dilakukan menggunakan uji-F. Pengujian dilakukan dengan tingkat signifikansi 0,05 . Hasil pengujiannya dapat dilihat pada tabel di bawah.

Tabel 11.

Hasil Uji Simultan (Uji-F)

\begin{tabular}{llcccc}
\multicolumn{5}{c}{ ANOVA $^{\mathbf{b}}$} \\
\hline Model & $\begin{array}{c}\text { Sum of } \\
\text { Squares }\end{array}$ & $\boldsymbol{d} \boldsymbol{f}$ & F & Sig. \\
\hline $1 \quad$ Regression & 1.166 & 3 & 1.319 & $.278 \mathrm{a}$ \\
& Residual & 15.905 & 54 & & \\
& Total & 17.071 & 57 & & \\
\hline
\end{tabular}

a. Predictors: (Constant), Spiritual Q, Intelektual

Q, Emosional Q

b. Dependent Variable: Pemahaman Ak.

Sumber: Data primer diolah (2018)

Hasil uji simultan menunjukan nilai probabilitas signifikan lebih dari 0.05 dan $F_{\text {hitung }}$ lebih kecil dari $F_{\text {tabel. }}$ Dari hasil uji tersebut dapat disimpulkan bahwa kecerdasan intelektual, emosional dan spiritual secara bersama-sama tidak mempengaruhi mahasiswa dalam mempelajari ilmu akuntansi. Dengan demikian, hipotesis empat $\left(\mathrm{H}_{4}\right)$ dalam penelitian ini ditolak. Hasil penelitian ini tidak mendukung penelitian yang dilakukan oleh Aziz dan Mangestuti (2006), Tikollah, dkk (2006), dan Trihandini (2005) dimana kecerdasan intelektual, emosional, dan spiritual secara simultan memiliki pengaruh terhadap kinerja, agresivitas, dan sikap etis seseorang.

\section{SIMPULAN DAN SARAN}

Hasil yang didapatkan dalam penelitian ini yaitu dari ketiga kecerdasan 
yang diukur, hanya kecerdasan emosional yang memiliki pengaruh terhadap pemahaman akuntansi mahasiswa secara parsial. Sedangkan kecerdasan intelektual dan kecerdasan spiritual tidak memiliki pengaruh terhadap pemahaman akuntansi mahasiswa secara parsial. Sementara ketiga kecerdasan tersebut tidak berpengaruh terhadap pemahaman akuntansi mahasiswa secara simultan.

Hasil penelitian ini menolak penelitian yang dilakukan oleh Trisnawati dan Suryaningrum (2003). Dalam penelitian tersebut, kecerdasan emosional tidak memiliki pengaruh terhadap tingkat pemahaman akuntansi sementara dalam hasil penelitian ini, kecerdasan intelektual memiliki pengaruh terhadap pemahaman akuntansi mahasiswa.

Penelitian ini dilakukan hanya terbatas pada mahasiswa tingkat akhir. Akan lebih baik jika penelitian selanjutnya dapat dilakukan pada mahasiswa di semua tingkatan. Penelitian selanjutnya juga dapat mengeksplor setiap butir pertanyaan dalam kuesioner sehingga lebih spesifik peruntukannya. Dengan demikian kriteria kecerdasan baik kecerdasan intelektual, emosional, maupun spiritual yang diukur terwakilkan dalam butir pertanyaan secara menyeluruh.

\section{DAFTAR PUSTAKA}

Arman, Yosi. 2007. The Seven Dimensions of Spiritual Intelligence: An Ecumenical, Grounded Theory. 115th Annual Conference of the American Psychological Association - San Francisco, CA (pp. 17-20).

Aziz, Rahmat, dan Retno Mangestuti. 2006. Pengaruh Kecerdasan Intelektual, Kecerdasan Emosional Dan Kecerdasan Spiritual Terhadap Agresivitas Pada Mahasiswa UIN Malang. El-Qudwah: Jurnal Penelitian Integrasi Sains Dan Islam 1: 70-84.

Aziza, Nurna, dan Rissyo Melandy. 2006. Pengaruh Kecerdasan Emosional Terhadap Tingkat Pemahaman Akuntansi, Kepercayaan Diri
Sebagai Variabel Pemoderasi. Simposium Nasional Akuntansi IX Padang.

Clarken, Rodney H. 2009. Moral Intelligence in the Schools. Presented at the Annual Meeting of the Michigan Academy of Sciences, Arts and Letters, March. https://eric.ed.gov/?id=ED508485.

Damayanti, Titien. 2010. Pengaruh Pendidikan Tinggi Akuntansi Terhadap Kecerdasan Emosional Dengan On-The Job Training Sebagai Variabel Moderating. Simposium Nasional Akuntansi XIII Purwokerto.

Emmons, Robert A. 2000. Is Spirituality an Intelligence? Motivation, Cognition, and the Psychology of Ultimate Concern. The International Journal for the Psychology of Religion 10 (1): 3-26. https://doi.org/10.1207/S15327582IJ PR1001_2.

Ghozali, Imam. 2006. Aplikasi Analisis Multivariate dengan program SPSS: Cetakan IV. Badan Penerbit Universitas Diponegoro; Semarang.

Goleman, D. 2003. Emotional Intelligence, Kecerdasan Emosional, Mengapa EI lebih penting dari pada IQ. Jakarta : Gramedia Pustaka Utama.

Howard, Barbara B., Precious Guramatunhu-Mudiwa, dan Stephen R. White. 2009. Spiritual Intelligence and Transformational Leadership: A New Theoretical Framework. Journal of Curriculum and Instruction 3 (2): 54.

KBBI, 2016. Kamus Besar Bahasa Indonesia. Badan Pengembangan Bahasa dan Perbukuan, Kementerian Pendidikan dan Kebudayaan Republik Indonesia. Versi daring.

Mulawarman, Aji Dedi. 2006. Pendidikan Akuntansi Berbasis Cinta: Lepas dari Hegemoni Korporasi Menuju Pendidikan yang Memberdayakan dan Konsepsi Pembelajaran yang Melampaui. EKUITAS (Jurnal Ekonomi dan Keuangan) 12 (2): 
142-58.

https://doi.org/10.24034/j25485024. y2008.v12.i2.300.

Mulkhan, Abdul Munir. 1998. Religiusitas iptek: rekonstruksi pendidikan dan tradisi pesantren. Yogyakarta: Kerjasama Fak. Tarbiyah IAIN Sunan Kalijaga Yogyakarta dengan Penerbit Pustaka Pelajar.

Nisa, Khairun. 2009. Hidden Curriculum: Upaya Peningkatan Kecerdasan Spiritual Siswa. Lentera Pendidikan: Jurnal Ilmu Tarbiyah dan Keguruan 12 (1): 72-86. https://doi.org/10.24252/lp.2009v12 n1a6.

Novius, A., 2008. Perbedaan Persepsi Intensitas Moral Mahasiswa Akuntansi Dalam Proses Pembuatan Keputusan Moral (Studi Pada Mahasiswa Akuntansi S1, Maksi, Pendidikan Profesi Akuntansi (PPA) Universitas Diponegoro Semarang) (PhD Thesis). Program Pascasarjana Universitas Diponegoro.

Singh, Ajay S., dan Micah B. Masuku. 2014. Sampling Techniques \& Determination of Sample Size in Applied Statistics Research: An Overview. International Journal of Economics, Commerce and Management 2 (11): 1-22.

Stein, Steven, dan Howard Book. 2006. The $E Q$ Edge: Emotional Intelligence and Your Success.

Sternberg, Robert J. 2005. The Theory of Successful Intelligence. Interamerican Journal of Psychology 39 (2): 189-202.

Suwardjono. 2005. Teori Akuntansi Perekayasaan Pelaporan Keuangan. 3rd ed. Yogyakarta: BPFE.

Tikollah, M. Ridwan, Iwan Triyuwono, dan Unti Ludigdo. 2006. Pengaruh Kecerdasan Intelektual, Kecerdasan Emosional, Dan Kecerdasan Spiritual Terhadap Sikap Etis Mahasiswa Akuntansi (Studi Pada Perguruan Tinggi Negeri Di Kota Makassar Provinsi Sulawesi
Selatan). Simposium Nasional Akuntansi 9: 23-26.

Trihandini, R. A. Fabiola Meirnayati. 2005. Analisis Pengaruh Kecerdasan Intelektual, Kecerdasan Emosi, Dan Kecerdasan Spiritual Terhadap Kinerja Karyawan (Studi Kasus Pada Hotel Horison Semarang). Masters, Program Pascasarjana Universitas Diponegoro. http://eprints.undip.ac.id/10280/.

Trisnawati, Eka Indah, dan Sri Suryaningrum. 2003. Pengaruh Kecerdasan Emosional Terhadap Tingkat Pemahaman Akuntansi. Simposium Nasional Akuntansi VI. Surabaya.

Yuniani, Anggun, dan Sugeng Pamudji. 2010. Pengaruh Kecerdasan Emosional Terhadap Tingkat Pemahaman Akuntansi. Tesis, Universitas Diponegoro.

Zohar, Danah, dan Ian Marshall. 2004. Spiritual Capital: Wealth We Can Live By. San Francisco: BerrettKoehler Publishers.

\section{PROFIL SINGKAT}

Muhammad Daud bin Mahmud, lahir di Allang.asaude (kabupaten seram bagian barat provinsi Maluku) pada tanggal 16 Agustus 1990. Gelar Sarjana Ekonomi (SE) diperoleh dari jurusan Akuntansi Fakultas Ekonomi Universitas Muhammadiyah Maluku Utara pada tahun 2013. Gelar Master of Accounting (M.Acc) diperoleh dari program magister akuntansi Universitas Gadjah Mada pada tahun 2017. Saat ini bekerja sebagai dosen tetap di program studi Akuntansi Syariah Institut Agama Islam Negeri (IAIN) Ternate. 